\title{
Reflections on Student-University Interactions for Next Generation Learning
}

\author{
David H. Wong \\ Curtin University, Australia
}

\begin{abstract}
Purpose - This paper draws attention to the implications of an e-learning strategy - a strategy that is increasingly employed with greater intensity by many higher education institutions, by re-examining the value creation process from a service-dominant logic perspective.

Design/methodology/approach - A model of student-faculty and student-student interactions using interactive Web 2.0 technologies in e-learning is offered and explained using literature from service-dominant logic research.

Findings - This perspective fundamentally alters the mindset of higher education institutions that have traditionally devised strategies to deliver value through its products and services. The new focus provided by service-dominant logic is for higher education institutions to acknowledge that they can only facilitate the value creation process by fostering interactions, constructing learning activities that enable enriching learning experiences and creating structures to support these experiences.

Practical implications - Key challenges for higher education institutions are discussed that include implications for exclusion marketing, perceived value for money, and policy issues.

Originality/value - This paper provides a fresh perspective, and a new line of thinking with regard to how value is co-created by both faculty and students through a set of experiences within student-faculty and student-student interactions. It therefore potentially directs a new path of research in the area.
\end{abstract}

Keywords - Marketing education, value creation, service-dominant logic, e-learning, Web 2.0 technology.

Paper type - Viewpoint.

\section{About the Author}

Dr. David H. Wong is the Chair of Teaching and Learning at the School of Marketing, Curtin University, Australia. His research revolves around topics in innovation and the diffusion of technology, service quality, electronic modes of delivery, and emotional value in the banking and higher education sectors. Dr. Wong has been invited as a reviewer for many journals and conferences, and is keenly sought as a reviewer for texts in marketing research. He has consulted in a large number commercial market research projects for both the profit and notfor-profit sectors, and is an Associate of the Australian Marketing Institute, a Certified Practicing Marketer, and a Fellow of The Academy of Marketing Science.

\section{Corresponding Author Mailing Address, Phone and e-Mail}

Dr. David H. Wong

Curtin University

School of Marketing

GPO Box U1987 Perth

Western Australia 6845

Phone: +61 892663289

Fax: +61 892663937

Email: David.Wong@cbs.curtin.edu.au 


\title{
Reflections on Student-University Interactions for Next Generation Learning
}

\author{
David H. Wong \\ Curtin University, Australia
}

\begin{abstract}
Purpose - This paper draws attention to the implications of an e-learning strategy - a strategy that is increasingly employed with greater intensity by many higher education institutions, by re-examining the value creation process from a service-dominant logic perspective.

Design/methodology/approach - A model of student-faculty and student-student interactions using interactive Web 2.0 technologies in e-learning is offered and explained using literature from service-dominant logic research.

Findings - This perspective fundamentally alters the mindset of higher education institutions that have traditionally devised strategies to deliver value through its products and services. The new focus provided by service-dominant logic is for higher education institutions to acknowledge that they can only facilitate the value creation process by fostering interactions, constructing learning activities that enable enriching learning experiences and creating structures to support these experiences.

Practical implications - Key challenges for higher education institutions are discussed that include implications for exclusion marketing, perceived value for money, and policy issues.

Originality/value - This paper provides a fresh perspective, and a new line of thinking with regard to how value is co-created by both faculty and students through a set of experiences within student-faculty and student-student interactions. It therefore potentially directs a new path of research in the area.
\end{abstract}

Keywords - Marketing education, value creation, service-dominant logic, e-learning, Web 2.0 technology.

Paper type - Viewpoint.

\section{Introduction}

The contemporary operations of higher education institutions (HEIs) have to an extent ceased to enjoy the relative autonomy and the geographic monopolies that predominated in the past. Preceding these changes are various environmental factors that have altered the way HEIs operate. For example, the increasing competitive work culture in many developed economies and the aging population have decreased the potential number of prospective students; and federal and state education cutbacks have led to increasing competitiveness between institutions for over two decades (Dolinsky and Quazi, 1994). Over the last decade or so, a new type of HEI has begun to emerge, being enabled most significantly by technological advances through the Internet. These technological developments have added a new competitive dimension with the emergence of two distinctive trends; the increased use of elearning mechanisms by traditional HEIs, and businesses specializing in Internet based learning solutions (Allen and Seaman, 2008).

The implementation of an e-learning strategy holds several obvious advantages for HEIs. It improves the financial standing of the HEI through the reduction of both variable and infrastructure costs, provides a source of differentiation and competitive advantage, provides global reach, adds another communication and feedback channel in student-HEI interactions, and potentially increase student satisfaction through the reduction of class sizes and thus 
improving service performance. As can be appreciated, the benefits of an e-learning strategy to HEIs are manifold, and have led many HEIs to invest significant resources and effort to its successful deployment.

\section{A New Operating Environment}

In recent years, e-learning has experienced phenomenal growth and has evolved from being an alternative mode of study for distance education students to become one of the main modes of delivery employed by HEIs in the broader ecology of blended learning. The flexibility brought about by e-learning had initially presented HEIs an opportunity to expand their market bases both nationally and internationally in the bid to remain competitive (Binsardi and Ekwulugo, 2003; Ivy, 2001), and increasingly HEIs are now extending their use of these technologies to include the utilization of interactive Web 2.0 tools such as blogs, wikis, social media and virtual worlds in virtual learning environments (VLEs) that further liberate themselves from the spatial constraints of their 'brick and mortar' campus. For example, not long after the first release of the iPad in 2010, the iPad had quickly gained popularity with both faculty and students who use the device to access VLEs such as Blackboard ${ }^{\mathrm{TM}}$ and Moodle ${ }^{\mathrm{TM}}$ for course learning resources, contribute to online blogs and reflective journals, and attend virtual classrooms facilitated by platforms such as Elluminate ${ }^{\mathrm{TM}}$. These technologies and their "apps" are continually evolving, and the use of social media such as Facebook have shown potential in building an enthusiasm for learning and a sense of community within the student cohort (English and Duncan-Howell, 2008; McLoughlin and Lee, 2008). Table 1 provides a list of some examples of Web 2.0 tools and their uses in teaching and learning.

\section{- Insert Table 1 here -}

Early studies in the use of technology in learning have found flexibility to be a key benefit (Malhotra, 2002), but with this flexibility, the result was also a loss of interaction between students and instructors (Kriger, 2001; Clark, 2000). Subsequently, this had prompted authors such as Paladino (2008), and Mood, Stewart and Bolt-Lee (2002) to consider how technology may be successfully incorporated in traditional classroom environments. However, new features of e-learning technology incorporating Web 2.0 tools now have a real potential to replace traditional classrooms. With an increasing student cohort adopting these technologies, the way faculty interact with students have changed. HEIs are now increasingly faced with a conundrum: while the next generation of students classified as 'digital natives' (see Prensky, 2001, 2009; Oblinger and Oblinger, 2005, Jones, Cross and Healing, 2010) may appreciate the flexibility that comes with e-learning; as they migrate away from traditional classroom environments to VLEs, the extent of personal face-to-face interaction with faculty decreases as spatial distance between the students and the HEI's physical campus increases.

With the advent of these new technologies and its corollary of service separation, an increasing number of HEIs have been redefining the manner in which they interact with their students. Some of the fundamental precepts of marketing thinking, including what we read in our textbooks - such as delivering customer value and customer satisfaction - have again become open concepts in this new operating environment. The contribution of this paper is thus to discuss the consequences of this change by re-examining how value is created in the student-HEI relationship for next generation learners. A service-dominant logic perspective is 
discussed that provides insights for key challenges for HEI's management and future research needs in the area.

I now turn my attention to further examining the issues faced by HEIs from a servicedominant logic perspective.

\section{Through the Lens of Service-Dominant (S-D) Logic of Marketing}

From a marketing viewpoint, a key consequence of the new operating environment for HEIs is the concept of value creation. Value creation is a significant driver of marketing strategy and forms the fundamental basis for interactions within the student-HEI relationship. Indeed, it has been suggested that value creation should be the fundamental basis for all marketing activities (Woodruff, 1997; Holbrook, 1996).

The fundamental definition of value is the trade between benefits and sacrifices - a view that is strongly influenced by the economics of marketing exchange. Over the last two decades, there have been extensive literature on the concept of value creation, and how value may be packed into a product and delivered to the customer. Recent literature has extended this view to define value as multi-dimensional in nature (e.g., Babin and James, 2010; Holbrook, 2005; Sweeney and Soutar, 2001). For example, Holbrook's (2005) definition considers value from an experiential perspective, which incorporates a wide range of factors apart from economic factors. Babin and James (2010) suggest that the emerging multidimensional value definition allows one to move beyond the goods-dominant (G-D) logic of marketing, to focus on actions and experiences rather than costs and benefits.

With the emergence of the S-D logic of marketing (see Vargo and Lusch, 2004; Lusch, Vargo and Tanniru, 2010), value is now seen as a measure for assessing the extent to which a service has succeeded (Babin and James, 2010). Two of the key foundational premises (FP) of S-D logic (see Vargo, 2009) that hold particular relevance to the context of our discussion is that the customer acts as a co-creator of value (FP6), rather than a consumer or destroyer of value; and that an enterprise only offers value propositions to the customer through its resources (FP7). I believe this perspective can be successfully applied to the student-HEI relationship, particularly in the current environment of service separation brought about by e-learning. From a S-D logic perspective, I note that students are increasingly moving into a role of being co-creators of value with the HEI, where students are active participants in the co-production of their learning outcomes. This perspective has become more relevant as e-learning moves to incorporate more interactive Web 2.0 tools, where the student is expected to create content and act as co-teachers in an environment that fosters experiential learning (Stavenga de Jong et al., 2006). Current thoughts on pedagogy support this view by defining learning as a process that the student experiences rather than a product that is sold to the student (Seaman, 2008). Thus, if we take that the role of the HEI is to provide a set of operant resources (skills, knowledge of instructors, and learning mechanisms such as e-learning platforms), and students co-create value for themselves depending on how they interact with these resources; the process of value creation becomes of critical importance to understanding the relationship the student has with the HEI. With this viewpoint, I emphasize here that value creation is process-based and process-driven, rather than exchange-driven, whereby traditionally it was seen that value was created by the HEI's faculty and then transferred to the student. I highlight the urgent necessity to better understand this process-based nature of value creation in higher education. 
Figure 1 illustrates the difference in student-faculty interactions through the lens of S-D logic.

- Insert Figure 1 here -

\section{Drivers of Value}

Given this perspective of S-D logic, I define value creation in the student-HEI relationship as the set of student experiences within student-faculty and student-student interactions that utilize HEI operant resources in learning activities to achieve set learning outcomes. It is important to note that the focal point is the student and not the HEI. This relates strongly to the view held by Heinonen et al. (2010) who propose that marketing should start considering an in-depth understanding of customer experiences. The ultimate outcome of a HEI's efforts should therefore be to construct and maintain pedagogically sound tools in learning environments to support the set of student experiences, resulting in 'value-in-use' (see Grönroos, 2006, 2008) for students.

From the above definition, the central question that arises is how HEIs can support (1) students' ongoing interactions, (2) learning activities and (3) experience structures. First, interaction is a key source of value - in the interactive process with a firm's operant resources, the customer is able to realize the value that emerges (Grönroos and Ravald, 2009; Smith and Colgate, 2007). This particular source of value is believed to derive from joint participation where both customer and firm interact, participate and collaborate to achieve valued outcomes for the customer (Grönroos, 2011). Recent literature have provided some insights such as the firm's ability to create dialog as an effective way to co-create value (Ballantyne and Varey, 2008; Lusch and Vargo, 2006; Lusch, Vargo and Tanniru, 2010). In the context of e-learning, it would be prudent to extend this view of value creation through firm-customer interactions to include customer-to-customer interactions, or in this case to account for both student-faculty and student-student interactions. Future iterations of elearning technology should focus on building facilities to support these levels of interactions in a bid to bolster value creation and close the spatial distance or 'transactional distance' that inherently exists in employing such technology (Dron, 2007). Through this, the HEI's role is to facilitate collaboration to achieve personalized learning and open discussion. Such facilitation of interaction has also been seen to influence quality perceptions of the online course (Peltier, Schibrowsky and Drago, 2007; McLoughlin and Lee, 2010).

Second, learning activities designed by faculty have the potential to foster greater student engagement and interest to interact. The efforts faculty makes in their engagement with students have long been documented to have a positive influence on a student's interest in the material as well as effective learning (e.g., Brophy, 1986). Students want teachers to make the subject 'alive', make it relevant to today's circumstances and involve the students in activities that cultivate active learning. This depicts an instructor that is flexible in approach and uses varied learning activities to make the subject matter more interesting or relevant. These learning activities should encourage students to be active participants in the learning process rather than be passive recipients. In e-learning, these sources of value may be achieved through a set of Web 2.0 tools working within the principles of social constructivism (see Barab et al., 2007; Jones, 2011; Willey and Burke, 2011) and constructionism (see HmeloSilver, Duncan and Chinn, 2007; Kim, 2005) - where in social constructivism, student groups construct knowledge for one another, collaboratively creating a small culture of shared 
resources; and in constructionism, students construct their knowledge and understanding through a set of experiences based on solving set problems. To illustrate, social constructivist approaches has as a central principle that knowledge is created by learners in the context of and as a result of social interaction. A group of students might be involved in the production of an assessment task directly in a wiki, but also be guided by a faculty member who provides scaffolding in the same wiki (McLoughlin and Lee, 2010). This scaffolding could take the form of wiki page structure and titles for pages to be filled in by the students, guidance as to areas to discuss in the wiki, and even feedback on existing student produced content (e.g., see Elgort, Smith, and Toland, 2008). Here, the wiki is the mediating mechanism between collaborating students and between students and faculty, acting as the conduit for value creation. The principles of constructionism may be similarly applied using social media to aid experiential learning approaches. Students may produce a podcast or video presentation on interviews with industry personnel in a case study, utilize a blog as a reflective learning journal during or on completion of a field assignment (for individual work), or produce a set of wiki pages (for individual and group work). These examples highlight that the efficacy of these tools lies in their empowerment of students to create their own content for distribution to their peers rather than the use of technology for the mere dissemination of lectures or other instructor-centered information (Lee, McLoughlin and Chan, 2008).

Third, I define experience structures as the perceived characteristics of the service space within which interactions and value-creating activities are performed. Smith and Colgate (2007) referred to the service environment as a source of value, making reference to aspects of the physical environment such as retail store atmospherics and other physical aspects of the consumption experience. Similarly, in the traditional classroom learning model, there have been well documented research on the impact of the associated learning environment such as the physical classroom arrangement of desks and chairs, lighting, as well as psychological and social dimensions such as class participation and personalization (e.g., see Church, Elliot and Gable, 2001). In the next generation model of e-learning, these structures put in place to support the customer experience will be replaced by the characteristics of the VLE, and psychosocial dimensions controllable by the faculty member acting as the instructor or facilitator of the interaction processes. In this, I propose eight dimensions of experience structures (ES1-8) and their conceptual definitions that I see are necessary to support value creating interactions and experiences in this context. These dimensions of experience structures adopt the view of Payne, Storbacka and Frow's (2008) perspective of the importance of 'encounter processes' and 'encounter design' to facilitate interactions and cocreation opportunities. Dimensions (ES1), (ES2) and (ES3) thus relate to necessary characteristics of the VLE and interaction protocols, dimensions (ES4), (ES5) and (ES6) relate to the nature and intensity of relationships between participants that foster interaction, while dimensions (ES7) and (ES8) relate to perceptions of learning resources that cultivate active learning:

(ES1) System integrity, the extent to which the VLE, and the associated Web 2.0 tools utilized are perceived to be reliable, responsive, controllable and behave as to be expected;

(ES2) Technical ease of use, the extent to which same are easy to navigate, logically laid out and clear in relaying expected inputs;

(ES3) Alternative processes, the extent to which processes and protocols are flexible, and the availability of alternative mechanisms for contacting faculty for assistance, clarification, and assessment submission; 
(ES4) Personalization, the extent to which students have the opportunity to informally interact with teaching staff;

(ES5) Cohesiveness, the extent to which students are willing to help each other and share vital information, exhibit shared values and openness;

(ES6) Inclusion, the extent to which all students feel valued and have an opportunity to participate, knowing that they are able to make a difference to their own and others learning goals;

(ES7) Trust, the extent to which students are confident about the efficacy of learning resources and are able to rely on both faculty and in particular fellow-student generated content for their learning; and finally,

(ES8) Relevance, the extent to which the assessments tasks and illustrations used in teachings is perceived to be authentic, personally relevant and exciting to the students.

Keeping in mind the precept of the preceding discussion that value is created through interaction maintenance and constructivist learning activities, these necessary experience structures by definition provide the 'lubricant' to ensure the mechanics of value creation are working smoothly, and without such experience structures, the process of value creation may be in jeopardy.

I now turn my attention to discuss some of the key challenges faced by HEIs for next generation learning.

\section{Key Challenges for Next Generation Learning}

HEIs have traditionally been product-based organizations, with faculty members and academics having substantial power to determine 'product offerings' (programs, courses) and delivery methods. The emergence of e-learning as a major pedagogical instrument has fundamentally transformed the way HEIs traditionally operate and how faculty interacts with students. The S-D logic perspective of the next generation learning model is a student centric model that has as its fundamental precept the student's ability to interact with faculty and other members of the student cohort to create value. The preceding discussion of the drivers of value holds several key challenges for HEIs. HEIs will need to build institutions that clearly understand which consumers they are targeting, what those consumers need, and the structures that support the interactions and experiences that occur in the value creation process. Having relatively recently embraced the concept of marketing, some HEIs have made some progress in this regard. The experience of other industry sectors, however, suggests that this fundamental shift in mindset will need to go much further to drive success.

\section{Segmentation, Compliance and Exclusion}

Consider this illustration in the air travel sector: many airline companies are extremely strict on check-in and aircraft boarding times and show no recourse for late passengers. This is certainly very disheartening should you be one of the late passengers, but is it so disheartening for the other 200 passengers who were on time and waiting in the aircraft? If the airline waited for you, they would make you a very delighted customer, but at the same time, there would be a further 200 customers already onboard that would be somewhat dissatisfied. In this illustration, the accommodation of 'bad' customers has a severe negative impact on the value realized by the 'good' customers who complied with the airline's protocols. Compliance with these protocols, and the exclusion of customers who do not comply, benefits the vast 
majority of customers and has the potential to further reduce costs - in the airline's case, aircraft downtime and the possibility of losing its take-off slot.

As HEIs move toward a model of value co-creation, students are able to be active participants in content sharing opportunities to create learning material and act as co-teachers in the coproduction of learning material. Keeping in mind that in this model value is created by the experiences of all actors involved in the interaction process (Prahalad, 2004; Prahalad and Ramaswamy, 2004), the question arises as to whether particular types of students are 'good' or 'bad' as co-producers in this process. The acceptance of certain 'bad' students into online courses that adopt the next generation learning model has the potential to negatively impact on the value creating processes of the rest of the student cohort. There is currently a divergence of opinion as to whether particular types of students can create significantly good learning materials using Web 2.0 tools. This is an interesting area where evidence will only emerge through time and future research. In some sense 'student' creation of learning materials is already happening - if one acknowledges that Wikipedia is a learning resource that contains learning materials. However, if you were like myself, you would inform your students to never trust all that Wikipedia has to offer.

As noted earlier, two of the important experience structures that support value-creating interactions are student trust in the efficacy of learning resources (ES7), and its relevance (ES8). As students now have a greater impact on how they affect other student's learning, there needs to be formed a set of rules for student interactions and compliance, and a set of criteria used to exclude students who may potentially harm the learning process of other students, leading to substandard learning experiences and dissatisfaction across the board for every student. The former I will address later when I discuss policy implications, and the latter, I will discuss here from the viewpoint of segmentation.

HEIs have for some time utilized the notion of segmentation in some form. A fundamental example is that of offering distinctive programs for undergraduates and postgraduates. Other examples include geographic segmentation of international markets and segmentation based on major of study or career prospects. Currently, many HEIs are beginning to use benefit segmentation for their e-learning initiatives, using selling propositions such as flexibility of study, remote 24/7 access to learning, self-paced learning, among others. However, given the context of our discussion on how value is created, HEIs need to start thinking not in terms of whom their customers are for their online courses but rather figuring out who should not be their customer. This method of exclusion is a very different approach to that based on traditional segmentation strategies. Obviously, this is an area that requires further research. I will, however, offer my thoughts on the possibility of devising an exclusion strategy based on a segmentation of student learning styles. Research in the area of learning styles has been extensive; consequently, this body of work has presented several conceptualizations of the way a student approaches learning. The major stream of research in this area is founded on the deep and surface approaches to learning (Biggs, 1987; Entwistle, Hanley and Hounsell, 1979; Marton and Saljo, 1976). A deep approach to learning is characterized by students intending to seek meaning and understanding from the material being studied through elaborating and transforming the material. A surface approach to learning, however, is characterized by students intending to simply reproduce the material being studied through memorization tactics. While the surface approach to learning depicts learners in passive roles, students adopting deep approaches are active learners who are particularly suited to constructivist learning models such as that previously discussed as a driver of value in the next generation learning model. Here, the exclusion of surface learners in online courses has the potential to 
vastly enhance the value creation capabilities of deep learners interacting with one another, by overall improving the social environment or 'learning space' (Kolb and Kolb, 2005).

How HEIs transform this ideology to a working strategy is a major challenge, and beyond the scope of this paper. Such strategy, I acknowledge may need to navigate around segregation and equity issues, of which the pros and cons need to be weighed from a managerial and perhaps legislative standpoint. Regardless of the outcome, and from a value-maximizing standpoint, HEIs need to start by accepting the notion that some 'customers' are not worth including in certain e-learning modes.

\section{Industry Engagement, Authenticity and Perceived Value for Money}

Another factor that HEIs have largely failed to recognize is that inherent in the next generation model of e-learning is the use of self-service technology (SST). (I refer the interested reader to articles such as Collier and Sherrell (2010), Curran and Meuter (2007), and Meuter et al. (2005) for a good review of research in the area of SST.) IKEA provides an illustration of early forms of SST by encouraging the customer to carry out part of the service themselves, by selecting, loading and transporting self-assembly furniture themselves activities that traditional stores would have carried out by employing warehouse staff. The savings are passed on to the company's customers in the form of lower costs. More recent examples of SST incorporating the use of the Internet as a medium for self-service include budget airline companies allowing their customers to design their own service by optionally booking excess baggage allowances, priority boarding, and special meals or entertainment; and e-banking services that allow bank customers to check account balances, transfer funds and complete loan applications themselves without the need for additional support from bank officers.

While I have already discussed that the interactions involved in co-production will have many value co-creating opportunities; with the very nature of involving customers in the coproduction of their own services, comes the customer expectation that the savings would be passed on to themselves. This is certainly true in the illustrated examples where IKEA has passed on the savings in the form of cheaper prices, budget airline companies in the form of lower fares and online banks in the form of more attractive rates and lower fees. Certainly one way for HEIs to re-balance this perceived disparity in value for money is to lower course fees for online courses, but with the inescapable flow-on effects of unwanted re-positioning as a 'budget' course, this may not be a wise strategy for many established HEIs - though potentially a viable strategy for newer 'online-only' educational providers. A better response is for HEIs to develop greater ancillary products and services that are linked to the online course to help re-gain perceived value for money. Some HEIs have made some headway in this regard by providing online students with elaborate leather-bound welcome packs or free iPads to students enrolled in their online courses in the bid to create greater tangibility. But for a student who would potentially enroll into a number of courses in their degree program, the added value provided by subsequent free compendiums or iPads would very quickly diminish. HEIs need to take a further step to develop unique propositions linked to their online courses that are congruent with the value creating processes already happening - and not simply tagging on products of questionable relevance. For example, if the HEI was to develop industry linkages for face-to-face company visits, or short internships in the online student's local area, the physical third-party interactions with company personnel would compliment the existing value creating interactions in the online course with faculty and other fellow students and further assist to introduce professional skills to the curriculum (Kelley 
and Bridges, 2005). The implementation of the iPortfolio, and learning activities such as involvement in the Google Online Marketing Challenge (GOMC) is a step in the right direction - but more needs to be done in this area and across a greater number of courses. If one was to acknowledge that the role of the HEI is to prepare graduates for jobs in the real world rather than in virtual worlds and for them to adopt the heutagogical perspective of 'selfdetermined life-long learning' (Ashton and Newman, 2006), then online courses need to extend students' learning beyond the confines of the VLE to fully authentic real world industry experiences. Just because it is an online course should not mean that all of the student's learning happens in front of a computer screen.

The strategy to be adopted by HEIs to achieve this is again beyond the scope of this paper. It may range from a simple redesign of the assessment structure to provide more authentic real world learning activities, to a fully coordinated approach such as setting up a 'match-making' website where local businesses may lodge requests for 'mini-projects' to be completed and then matching projects with one or more online students residing in the area who would provide the service either on an individual or group basis. The developmental costs to HEIs would naturally be incremental through this range of strategies, but HEIs that adopt such coordinated strategies to successfully contribute toward students' academic, personal and career development would clearly have the competitive edge (McIlveen and Pensiero, 2008).

\section{Policy Implications and Other Implementation Issues}

The use of Web 2.0 and social media tools are increasingly part of our daily lives. Use of such interactive tools in education draw out several issues that have been fiercely debated in academic boards and senior leadership circles of HEIs as well as in numerous web forums; with 'experts' presenting both sides of issues such as why teachers should or should not be Facebook friends with their students, risk management strategies to prevent embarrassing posts by individual staff members that may harm the reputation of the HEI, among others.

Consequently, many HEIs have started to acknowledge the need for formal policies and guidelines governing the use of social media and other RSS feeds. These have largely been adopted from industry and have predominantly been generic in nature - centering around issues such as code of conduct (e.g., "be respectful", "be truthful", "think before you post", etc.), copyright issues, use of disclaimers, confidentiality of information, taboo topics and content, and more generally how to use such tools 'positively' following overarching philosophies such as 'do no harm'.

Rightly so, these policies and guidelines exist to protect HEIs from potential legal repercussions of misuse. However, the introduction of these tools now as powerful mechanisms to facilitate interactions and value co-creation in teaching has drawn out several other issues that are not currently addressed by the majority of HEIs. As students take on the role as co-producers of learning material, questions of ownership, re-usability, control, and censorship of student-generated content emerge; as do personal security issues such as cyber bullying, student equity and accessibility issues, and the need to govern what is appropriate student-faculty relationships on social media such as Facebook and Twitter (e.g., in some cases, the use of social media such as Facebook had been shown to reduce teacher credibility (Mazer, Murphy and Simonds, 2007). These issues demand responses at the policy and strategic level. HEIs need to consider these issues and the risks to the institution associated with either internally or externally hosting Web 2.0 services, ways in which these risks can be controlled, and to clearly define policies and guidelines that give best practices to faculty and 
students and show where and how to use these tools to optimum effect from a teaching-use perspective.

Off the starting block, Harvard Law School (HLS) and a handful of other educational providers have attempted to address issues of ownership of student-generated content, pioneering the use of creative commons licenses (see www.creativecommons.org) in governing the use of student-generated content in blogs, wikis and other Web 2.0 services. Under the "Attribution Share Alike" license adopted by HLS, copyright owners permit faculty and other students to share, re-use and remix their material legally and royalty-free, but the terms of this license must be agreed upon by students prior to the use of these tools within HLS's VLE. HLS actively monitors student content and has the sole discretion to delete any content deemed inappropriate.

While HLS and certain others have taken a great leap forward in addressing some of the highlighted issues, there needs to be a more concerted effort by HEIs to adopt similar policies on an institution-wide basis, and to devise associated protocols for the infringement of such policies (see Keats, 2009 for an example of the experiences of a HEI in implementing such an institution-wide policy). However, because of the relative immaturity of Web 2.0 technology and in particular its current infancy in teaching and learning, I would suggest that such policies initially not be overly prescriptive so as to stifle its continued experimentation and growth.

\section{Conclusion}

This paper had drawn attention to the implications of an e-learning strategy - a strategy that is increasingly employed with greater intensity by many HEIs in response to increased competition, prevailing difficulties in sourcing funding, and an attempt to cater to the changing needs of the next generation of learners who have spent their formative years in the digital age. Advances in technology have changed the way many HEIs interact with their students. In particular, new features of e-learning technology incorporating Web 2.0 tools now have a real potential to replace traditional classrooms. These interactive learning platforms solve the age old criticism of e-learning's lack of interactivity by turning learners into coteachers with the sharing of students' thoughts, ideas and other content through blogs, wikis, social media and virtual worlds.

As many groups of students become more content with interacting with their faculty remotely through these technologies, the implications for student-HEI relationships are important. There is an urgent necessity to re-examine how value is created in these relationships. The $S$ D logic perspective discussed provided a fresh perspective, and a new line of thinking with regard to how value is co-created by both faculty and students through a set of experiences within student-faculty and student-student interactions. This viewpoint has the potential to fundamentally alter the mindset of HEIs who have traditionally devised strategies to deliver as much value as possible through its products and services. The new focus provided by S-D logic is rather for HEIs to acknowledge that they can only facilitate the value creation process by fostering rich interactions, constructing learning activities that enable enriching learning experiences and creating structures to support these experiences.

While the objective of this paper in discussing these perspectives on value creation in the student-HEI relationship have been fulfilled, I concede that new questions have been opened in the process - for example, should exclusion strategies be applied? If so, on what basis 
should exclusion be applied? Which of the experience structures proposed contribute most to interactions and hence value creation? How can HEIs assist faculty in this regard? What are the implications for HEI positioning and branding? In this, the perspective taken in this paper therefore potentially directs a new path of research in the area of next generation learning.

\section{References}

Allen, I.E. and Seaman, J. (2008), Staying the course: Online education in the United States, Sloan Consortium, Needham, MA, USA.

Ashton, J. and Newman, L. (2006), "An unfinished symphony: 21st century teacher education using knowledge-creating heutagogies", British Journal of Educational Technology, Vol. 37 No. 6, pp. 825-84.

Babin, B. J. and James, K. W. (2010), "A brief retrospective and introspective on value", European Business Review, Vol. 22 No. 5, pp. 471-478.

Ballantyne, D. and Varey, R. J. (2008), "The service-dominant logic and the future of marketing”, Journal of the Academy of Marketing Science, Vol. 36 No. 1, pp. 11-14.

Barab, S.A., Dodge, T., Thomas, M., Jackson, C. and Tuzun, H. (2007), "Our designs and the social agendas they carry", Journal of the Learning Sciences, Vol. 16 No. 2, pp. 263305.

Biggs, J. (1987), Student approaches to learning and studying. Melbourne: Australian Council for Educational Research.

Binsardi, A. and Ekwulugo, F. (2003), "International marketing of British education: Research on students' perception and the UK market penetration", Marketing Intelligence and Planning, Vol. 21 No. 5, pp. 318-327.

Brophy, J. (1986), "Teacher influences on student achievement", American Psychologist, Vol. 41 No. 10, pp. 1069-1077.

Church, M.A., Elliot, A.J. and Gable, S.L. (2001), "Perceptions of classroom environment, achievement goals, and achievement outcomes", Journal of Educational Psychology, Vol. 93 No. 1, pp. 43-54.

Clark, M. (2000), "Students on silicon campus", The Guardian Online, No. 9, pp. 2-3.

Collier, J.E. and Sherrell, D.L. (2010), "Examining the Infiuence of Control and Convenience in a Self-Service Setting", Journal of the Academy of Marketing Science, Vol. 38 No. 4, pp. 409-509.

Curran, J.M. and Meuter, M.L. (2007), "Encouraging Existing Customers to Switch to SelfService Technologies: Put a Little Fun into Their Lives", Journal of Marketing Theory and Practice, Vol. 15 No. 4, pp. 283-298.

Dolinsky, A.L. and Quazi, H.A. (1994), "A Diagnostic Technique for Formulating Marketing Strategies in Higher Education Based on Relative Competitive Position", Journal of Marketing for Higher Education, Vol. 5 No. 2, pp. 89-101.

Dron, J. (2007), "Designing the Undesignable: Social software and control", Educational Technology \& Society, Vol. 10 No. 3, pp. 60-71.

Elgort, I., Smith, A.G. and Toland, J. (2008), "Is wiki an effective platform for group course work?", Australasian Journal of Educational Technology, Vol. 24 No. 2, pp. 195-210.

English, R. and Duncan-Howell, J. (2008), "Facebook goes to college: Using social networking tools to support students undertaking teaching practicum", MERLOT Journal of Online Learning and Teaching, Vol. 4 No. 4, pp. 596-601.

Entwistle, N., Hanley, M. and Hounsell, D. (1979), "Identifying distinctive approaches to studying", Higher Education, Vol. 8 No. 4, pp. 365-380.

Grönroos, C. (2006), “Adopting a service logic for marketing”, Marketing Theory, Vol. 6 No. 3 , pp. 317-333. 
Grönroos, C. (2008), “Service logic revisited: who creates value? And who co-creates?", European Business Review, Vol. 20 No. 4, pp. 298-314.

Grönroos, C. (2011), "A service perspective on business relationships: The value creation, interaction and marketing interface", Industrial Marketing Management, Vol. 40 No. 2, pp. 240-247.

Grönroos, C. and Ravald, A. (2009), Marketing and the Logic of Service: Value Facilitation, Value Creation and Co-creation, and their Marketing Implications, Hanken Publishing, Helsinki, Finland.

Heinonen, K., Strandvik, T., Mickelsson, K.-J., Edvardsson, B., Sundström, E. and Andersson, P. (2010), "A customer-dominant logic of service", Journal of Service Management, Vol. 21 No. 4, pp. 531-548.

Hmelo-Silver, C.E., Duncan, R.G. and Chinn, C.A. (2007), "Scaffolding and Achievement in Problem-Based and Inquiry Learning: A Response to Kirschner, Sweller, and Clark (2006)", Educational Psychologist, Vol. 42 No. 2, pp. 99-107.

Holbrook, M.B. (1996), "Customer Value - A Framework For Analysis and Research", Advances in Consumer Research, Vol. 23 No. 1, pp. 138-142.

Holbrook, M.B. (2005), "Customer value and autoethnography: subjective personal introspection and the meanings of a photograph collection", Journal of Business Research, Vol. 58 No. 1, pp. 45-61.

Ivy, J. (2001), "Higher education institution image: A correspondence analysis approach", International Journal of Education Management, Vol. 15 No. 6, pp. 276-282.

Jones, C., Ramanau, R., Cross, S. and Healing, G. (2010), "Net generation of Digital Natives: Is there a distinct new generation entering university?", Computers and Education, Vol. 54 No. 3, pp. 722-732.

Jones, I.M. (2011), "Can You See Me Now? Defining Teaching Presence in the Online Classroom Through Building a Learning Community", Journal of Legal Studies Education, Vol. 28 No. 1, pp. 67-116.

Keats, D. (2009), "The road to Free and Open Educational Resources at the University of the Western Cape: A personal and institutional journey", Open Learning: The Journal of Open and Distance Learning, Vol. 24 No. 1, pp. 47-55.

Kelley, C.A. and Bridges, C. (2005), "Introducing professional and career development skills in the marketing curriculum", Journal of Marketing Education, Vol. 27 No. 3, pp. 212218.

Kim, J.S. (2005), "The Effects of a Constructivist Teaching Approach on Student Academic Achievement, Self-Concept, and Learning Strategies", Asia Pacific Education Review, Vol. 6 No. 1, pp. 7-19.

Kolb, A.Y. and Kolb, D.A. (2005), "Learning styles and learning spaces: Enhancing experiential learning in higher education", Academy of Management Learning and Education, Vol. 4 No. 2, pp. 193-212.

Kriger, T.J. (2001), A virtual revolution: Trends in the expansion of distance education, American Federation of Teachers, New York State United, http://www.aft.org/pdfs/highered/virtualrevolution0501.pdf. Retrieved 5th January 2012.

Lee, M.J.W., McLoughlin, C. and Chan, A. (2008), "Talk the talk: Learner-generated podcasts as catalysts for knowledge creation", British Journal of Educational Technology, Vol. 39 No. 3, pp. 501-521.

Lusch, R.F. and Vargo, S.L. (2006), The service-dominant logic of marketing :dialog, debate, and directions, Armonk, N.Y.: M.E. Sharpe.

Lusch, R.F., Vargo, S.L. and Tanniru, M. (2010), "Service, value networks and learning”, Journal of the Academy of Marketing Science, Vol. 38 No. 1, pp. 19-31. 
Malhotra, N.K. (2002), "Integrating technology in marketing education: Perspective for the new millennium", Marketing Education Review, Vol. 12 No. 3, pp. 1-5.

Marton, F. and Saljo, R. (1976), "On qualitative differences in learning: Outcome and processes", British Journal of Educational Psychology, Vol. 46 No. 1, pp. 4-11.

Mazer, J.P., Murphy, R.E. and Simonds, C.J. (2007), "I'll see you on "Facebook": The effects of computer-mediated teacher self disclosure on student motivation, affective learning, and classroom climate", Communication Education, Vol. 56 No. 1, pp. 1-17.

McIlveen, P. and Pensiero, D. (2008), "Transition of graduates from backpack-to-briefcase: a case study", Education and Training, Vol. 50 No. 6, pp. 489-499.

McLoughlin, C. and Lee, M.J.W. (2008), "Future learning landscapes: Transforming pedagogy through social software", Journal of Online Education, Vol. 4 No. 5, pp. 1-9.

McLoughlin, C. and Lee, M.J.W. (2010), "Personalised and self regulated learning in the Web 2.0 era: International exemplars of innovative pedagogy using social software", Australasian Journal of Educational Technology, Vol. 26 No. 1, pp. 28-43.

Meuter, M.L., Bitner, M.J., Ostrom, A.L. and Brown, S.W. (2005), "Choosing Among Alternative Service Delivery Modes: An Investigation of Customer Trial of Self-Service Technologies", Journal of Marketing, Vol. 69 No. 2, pp. 61-83.

Mood, J., Stewart, B., Bolt-Lee, C. (2002), "Showing the skilled business graduate: Expanding the tool kit", Business Communication Quarterly, Vol. 65 No. 1, pp. 21-36.

Oblinger, D.G. and Oblinger, J.L. (2005), Educating the net generation, Educause e-book publication, http://www.educause.edu/ir/library/pdf/pub7101.pdf. Retrieved 21st December 2011.

Paladino, A. (2008), "Creating an interactive and responsive teaching environment to inspire learning", Journal of Marketing Education, Vol. 30 No. 3, pp. 185-188.

Payne, A. F., Storbacka, K. and Frow, P. (2008), "Managing the co-creation of value", Journal of the Academy of Marketing Science, Vol. 36 No. 1, pp. 83-96.

Peltier, J.W., Schibrowsky, J.A. and Drago, W. (2007), "The interdependence of the factors influencing the perceived quality of the online learning experience: A causal model", Journal of Marketing Education, Vol. 29 No. 2, pp. 140-153.

Prahalad, C.K. (2004), "Co-creation experiences: The next practice in value creation", Journal of Interactive Marketing, Vol. 18 No. 3, pp. 5-14.

Prahalad, C.K. and Ramaswamy, V. (2004), "Co-creating unique value with customers", Strategy \& leadership, Vol. 32 No. 3, pp. 4-9.

Prensky, M. (2001), "Digital natives, digital immigrants", On the Horizon, Vol. 9 No. 5, pp. $1-6$.

Prensky, M. (2009), "H. sapiens digital: From digital immigrants and digital natives to digital wisdom", Journal of Online Education, Vol. 5 No. 3, pp. 1-9.

Seaman, J. (2008), "Experience, reflect, critique: The end of the 'Learning cycles' era", Journal of Experiential Education, Vol. 31 No. 1, pp. 3-18.

Smith, J.B. and Colgate, M. (2007), "Customer value creation: A practical framework", Journal of Marketing Theory \& Practice, Vol. 15 No. 1, pp. 7-23.

Stavenga de Jong, J.A., Wierstra, R.F.A., Hermanussen, J. (2006), “An exploration of the relationship between academic and experiential learning approaches in vocational education", British Journal of Educational Psychology, Vol. 76 No. 1, pp. 155-169.

Sweeney, J.C. and Soutar, G.N. (2001), "Consumer perceived value: The development of a multiple item scale", Journal of Retailing, Vol. 77 No. 2, pp. 203-220.

Vargo, S.L. (2009), "Toward a transcending conceptualization of relationship: a servicedominant logic perspective", Journal of Business \& Industrial Marketing, Vol. 24 No. 5-6, pp. 373-379. 
Vargo, S.L. and Lusch, R.F. (2004), "Evolving to a New Dominant Logic for Marketing", Journal of Marketing, Vol. 68 No. 1, pp. 1-17.

Willey, L. and Burke, D.D. (2011), "A Constructivist Approach to Business Ethics: Developing a Student Code of Professional Conduct", Journal of Legal Studies Education, Vol. 28 No. 1, pp. 1-38.

Woodruff, R. (1997), "Customer value: The next source for competitive advantage", Journal of the Academy of Marketing Science, Vol. 25 No. 2, pp. 139-153. 
Table 1: Examples and uses of Web 2.0 tools in teaching and learning

\begin{tabular}{|c|c|}
\hline Tool & Uses in teaching and learning \\
\hline Blogs & $\begin{array}{l}\text { Students could: } \\
\text { - Create a personal learning space where content is reused and remixed. } \\
\text { - } \quad \text { Provide feedback to fellow students' blog posts. } \\
\text { - Critique course readings. } \\
\text { - } \quad \text { Develop linkages with other students locally and internationally. }\end{array}$ \\
\hline Wikis & $\begin{array}{l}\text { Students could: } \\
\text { - Collaboratively complete group project work with fellow students. } \\
\text { - Develop a shared repository of resources. } \\
\text { - } \quad \text { Respond to discussion questions collaboratively. }\end{array}$ \\
\hline Podcasting & $\begin{array}{l}\text { Students could: } \\
\text { - Upload voice recorded self-reflections or interview assignments. } \\
\text { - Develop written and oral communication skills through the scripting } \\
\text { and production of a podcast. } \\
\text { - Produce and publish a digital narrative. }\end{array}$ \\
\hline RSS feeds & $\begin{array}{l}\text { Students could: } \\
\text { - } \text { Receive latest academic and industry news. } \\
\text { - } \text { Receive lecture recordings. } \\
\text { - } \text { Receive notifications when a learning resource has been added to the } \\
\text { class social bookmarking site. } \\
\text { - Selectively social bookmark key feed items. }\end{array}$ \\
\hline Elluminate & $\begin{array}{l}\text { Students could: } \\
\text { - Collaborate synchronously in brainstorming and mind mapping } \\
\text { activities. } \\
\text { - Interact with industry experts anywhere in the world. } \\
\text { - Engage with regional/distance students in an interactive tutorial. } \\
\text { - Actively participate in software demonstrations using shared media. }\end{array}$ \\
\hline iPortfolio & $\begin{array}{l}\text { Students could: } \\
\text { - Reflect on their own learning arising from curricular and extra- } \\
\text { curricular activities. } \\
\text { - Create, share and publish evidence of their learning achievements for } \\
\text { prospective employers. } \\
\text { - Maintain an online journal reflecting on work-integrated learning } \\
\text { experiences. }\end{array}$ \\
\hline
\end{tabular}


Figure 1: Next generation student-faculty interactions through the lens of S-D logic

\begin{tabular}{|c|c|}
\hline Traditional classroom learning & e-Learning through the lens of S-D logic \\
\hline $\begin{array}{l}\text { Group } \\
\text { interaction } \\
\text { Little to no inter- } \\
\text { group interaction } \\
\text { Group } \\
\text { interaction }\end{array}$ & \\
\hline $\begin{array}{l}\text { Key characteristics: } \\
\text { - Production of learning resources lies } \\
\text { with faculty. } \\
\text { - Faculty delivers value through } \\
\text { learning resources. } \\
\text { - Student group/tutorial interaction } \\
\text { possible, but little to no inter-group/ } \\
\text { tutorial interaction. }\end{array}$ & $\begin{array}{l}\text { Key characteristics: } \\
\text { - Faculty and students co-produce learning } \\
\text { resources. Students act as co-teachers in } \\
\text { VLEs through blogs and the creation of } \\
\text { podcasts. } \\
\text { - Co-creation of value through rich student- } \\
\text { faculty and student-student interactions } \\
\text { through wikis, social bookmarking and } \\
\text { virtual classrooms such as Elluminate. } \\
\text { Rich intra- and inter-group/tutorial } \\
\text { interactions enabled by Web } 2.0 \text { tools. } \\
\text { Greater scope for information sharing with } \\
\text { entire student cohort (e.g., via RSS feeds } \\
\text { and social bookmarking). }\end{array}$ \\
\hline
\end{tabular}

